\title{
Grade II Sylvian fissure meningiomas without dural attachment: case report and review of the literature
}

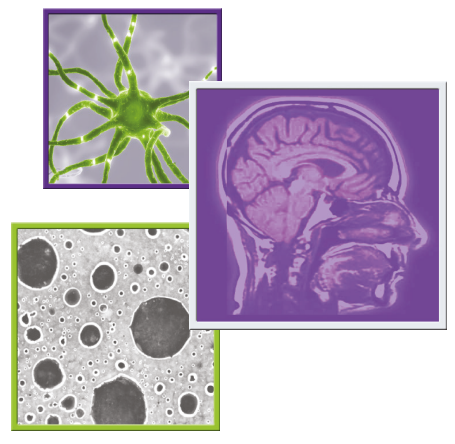

\author{
Christian Brogna*,1,2, José Pedro Lavrador ${ }^{1}$, Sabina Patel ${ }^{1}$, Eduardo C Ribas ${ }^{3}$, Miren \\ Aizpurua ${ }^{4}$, Francesco Vergani ${ }^{1}$, Keyoumours Ashkan ${ }^{1}$ \& Ranjeev Bhangoo ${ }^{1}$ \\ ${ }^{1}$ Department of Neurosurgery, King's College Hospital NHS Foundation Trust, London, UK \\ ${ }^{2}$ Institute of Psychiatry, Psychology \& Neuroscience, King's College London, London, UK \\ ${ }^{3}$ Division of Neurosurgery, Hospital das Clínicas, University of São Paulo Medical School, São Paulo, Brazil \\ ${ }^{4}$ Department of Neuropathology, King's College Hospital NHS Foundation Trust, London, UK \\ *Author for correspondence: christian.brogna@nhs.net
}

\section{Practice points}

- Sylvian fissure meningiomas are rare nondural-based lesions.

- Sylvian fissure meningiomas are more common in males and usually present with seizures.

- The anatomical relationship with the middle cerebral artery has prevented complete resections in the described cases.

- Preoperative vascular imaging and intraoperative angiography may improve surgical planning and safe complete tumoral resection rates.

Sylvianfissure meningiomas (SFMs) represent a rare subgroup of nondural-based tumors arising from the meningothelial cells within the arachnoid of the Sylvian fissure. SFMs are more frequent in young males, usually manifest with seizures and display the same radiological features of meningiomas in other locations. Although the absence of dural attachment makes these tumors suitable for a complete resection, their anatomical relationships with the middle cerebral artery branches have impaired its achievement in half of them. To the best of our knowledge, only five atypical WHO grade II SFMs have been previously described. We provide a literature review of SFMs WHO grades I-II and discuss common characteristics and surgical challenges we found in a similar case.

First draft submitted: 28 February 2018; Accepted for publication: 19 June 2018; Published online: 2 October 2018

Keywords: atypical meningiomas • dural attachment • meningioma • Sylvian fissure

Meningiomas are thought to arise from the meningothelial cells within the arachnoid and are typically recognized by their attachment to the dura. These cells can also be found in the choroid plexus and tela choroidea, which can explain why meningiomas may rarely occur in other locations without dural attachment. In the absence of dural attachment, they are categorized into intraventricular, pineal region, intraparenchymal, subcortical and deep Sylvian fissure meningiomas (SFMs) [1].

Meningiomas are most commonly supplied by dural arteries arising from external carotid system, but may develop a secondary supply via the pial arteries, such as the branches of the anterior, middle and posterior cerebral arteries from the internal carotid and vertebrobasilar systems [2].

Atypical meningiomas WHO grade II account for 5-7\% of all meningiomas and have a higher likelihood of recurring as they proliferate at a higher rate and can invade the brain [3]. As the role of complementary treatment is yet to be defined, the surgical approach and the extent of resection is of paramount importance in the prognosis. In those cases where no dural attachment is found, a complete resection of the tumor may represent the cure for these patients. 


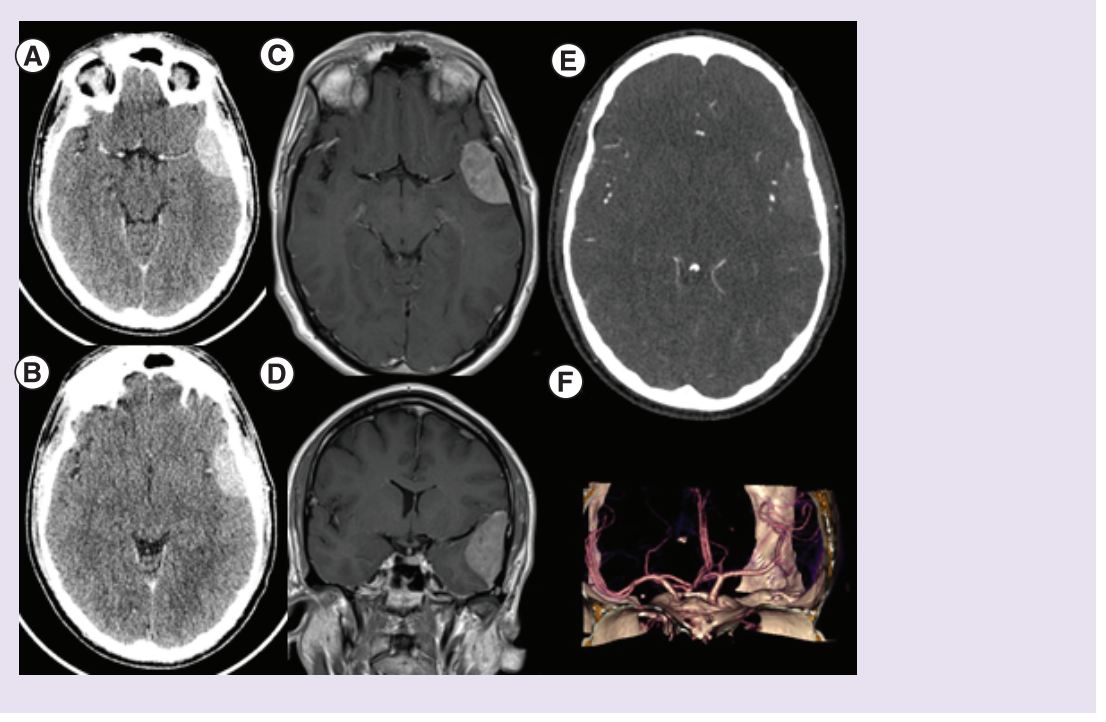

Figure 1. Pre-operative imaging. Axial-CT head with contrast ( $A$ and $B$ ) and axial (C) and coronal (D) MRI T1-weighted images with gadolinium revealing a homogenously enhancing left pterional region tumor. Axial angio-CT head $(E)$ and $3 D$ angio-reconstruction $(F)$ revealing the intrinsic relationship in between the left MCA branches and the lesion.

CT: Computed tomography; MCA: Middle cerebral artery; MRI: Magnetic resonance impaging; T1: Superior temporal gyrus.

The authors discuss a patient with an atypical WHO grade II SFM without dural attachment and review the previous literature centered on clinical, radiological, pathologic characteristics and treatment approach of this rare condition.

\section{Case report}

A 32-year-old right-handed charity worker with no significant past medical history presented with a year-long history of daily bitemporal and frontal headaches. The headaches were associated with dizziness and unsteadiness as well as nausea, phonophobia and photophobia. These symptoms then progressed in a month affecting the patient's activities of daily living. There was no associated history of seizures, speech disturbance or sensory/motor deficits and the neurological exam was unremarkable.

A computed tomography head and angio-computed tomography identified an hyperdense lesion in the left temporal convexity in close relation with the Sylvian fissure (M2 branches from left MCA) and the MRI-revealed and homogenous contrast-uptake lesion, consistent with a meningioma (Figure 1). A left pterional craniotomy was performed and, as soon as the dura was opened, it became evident that the tumor did not have any convexity or skull-based dural attachment. Proximal microsurgical opening of the Sylvian fissure was performed starting at the anterior Sylvian point, exposing the carotid artery for proximal control. Internal debulking of the tumor followed by gentle dissection of the capsule all along the arachnoidal plane from the surrounding brain parenchyma was performed while preserving the temporal M2 and M3 branches. However, a clear attachment of the meningioma to the arachnoid overlying the most anterior portion of the posterior insular gyrus became evident, and it was was dissected and coagulated. In fact, while a clear arachnoidal plane was identified all around the meningioma, an exception was made by the portion of the tumor facing the posterior insular gyrus (Figure 2).

The histological staining identified atypical features within the tumor specimens. There were areas of hypercellularity with small nuclei and areas of necrosis, but no evidence of increased mitotic activity and a low-proliferating index. The features were consistent with an atypical meningioma, WHO grade II. (Figure 3). The postoperative course was uneventful. The patient reported a consistent improvement in his headaches in the next days following the surgery. A follow-up MRI at 3 months did not reveal any recurrence of the tumor and the patient is under clinical and radiological surveillance with no signs of recurrence at 3 years' follow-up (Figure 4). 


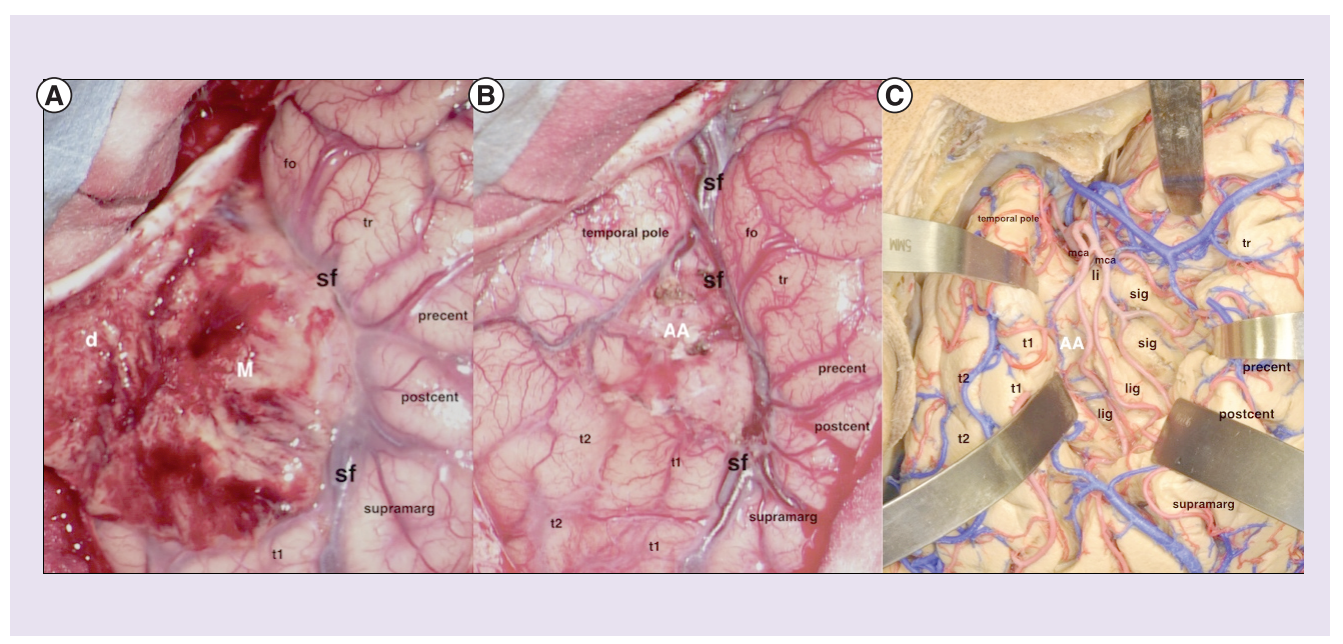

Figure 2. Intraoperative imaging and schematic review. Intraoperative photos before (A) and after (B) microsurgical resection of the SFM and correlation with an anatomical specimen with the same operative angle (C). (A) shows the clear absence of any dural attachment of the SFM. (B) shows the AA of the Sylvian fissure meningioma in correspondence of the anterior part of the posterior long insular gyrus. (C) The Sylvian fissure is opened and the relationships of the middle cerebral artery branches with the surrounding anatomical structures is unveiled. AA: Arachnoidal attachment; SFM: Sylvian fissure meningioma.

\section{Discussion}

Cushing and Eisenhardt originally classified meningiomas without dural attachment in intraventricular, subcortical and deep Sylvian [4]. Nowadays, meningiomas without dural attachments are classified in supratentorial (intraventricular, intraparenchymal or subcortical, pineal region, deep Sylvian) and infratentorial (intraventricular, inferior tela choroidea, cisterna magna and intraparenchymal) [5]. The most common lesions in this group occur in pediatric population and have an infratentorial location [6].

SFMs are rare entities and it is important to differentiate them from the sphenoid wing meningiomas. These are attached to the dura overlying the sphenoid wings, are usually associated with hyperostosis and they displace the MCA backwards as they grow, while the SFMs do not have dural attachment, do not produce hyperostosis and grow inbetween the MCA branches. Given the recent changes in the meningioma classification system, it is difficult to comment on the grades inbetween these locations, even though the literature presented suggests a higher proportion of grade II lesions among the SFMs [6]. Barcia-Goyanes et al. [7] described the first case in 1953, and since then only 28 cases (including the present report) have been described (Tables 1, 2 and 3). [8-26] The reported adult SFMs patients are young (mean age of $34.95 \pm 3.35$ years; 95\% CI [27.93-41.97]) with a M:F ratio of 1.22 $(11 / 9)$ and in the pediatric population (mean age is $5.71 \pm 1.61$ years; $95 \%$ CI [1.76-9.66]; the M:F ratio is 2:1 (4/2 and 1 unknown). When comparing grade I and grade II lesions, there is no significant differences in terms of mean age (grade I: $26.87 \pm 3.90$ years; vs grade II $24.33 \pm 7.01$ years; t-test $p>0.05$ ), gender (grade I M:F ratio $1.2[12 / 10]$ versus grade II M:F ratio - $5[5 / 1)]$ ), clinical presentation (seizures is the most common presentation in both groups - grade $1-74 \%(17 / 23)$ and grade II - 67\% (4/6)] and extent of resection (total resection in grade $1-65 \%[1 / 23]$ and total resection in grade II $-50 \%[3 / 6]$. (Table 4)

When considering the WHO grade II atypical meningiomas, only six lesions have been described (considering the present report; Table 3) $[6,9,11,16,21]$. Atypical meningiomas constitute $20 \%$ of the meningiomas in these region, higher than in other locations (5-7\%) as it has already been noted by Cecchi et al. [6]. Regarding its epidemiology, there is a clear male predominance (5/6) although there is no gender prevalence when considering all the SFMs; $5 / 6$ patients are aged below 32 years old. When considered together, male gender and younger aged are risk factors for WHO grade II histological differentiation in other locations, which is also true in this location [6]. Therefore, there are no sufficient data published that allow assessing if the Sylvian fissure location is a risk factor for WHO grade II lesions per se or if it has been confounded by these previously known epidemiological risk factors. Even though absent in the present case, seizures is the most frequent symptom which is believed to be related either with the temporal location and with the fact that WHO grade II tumors might show adjacent brain invasion as part of their diagnostic criteria. Surprisingly, considering its location and the histological nature of these lesions, no focal 


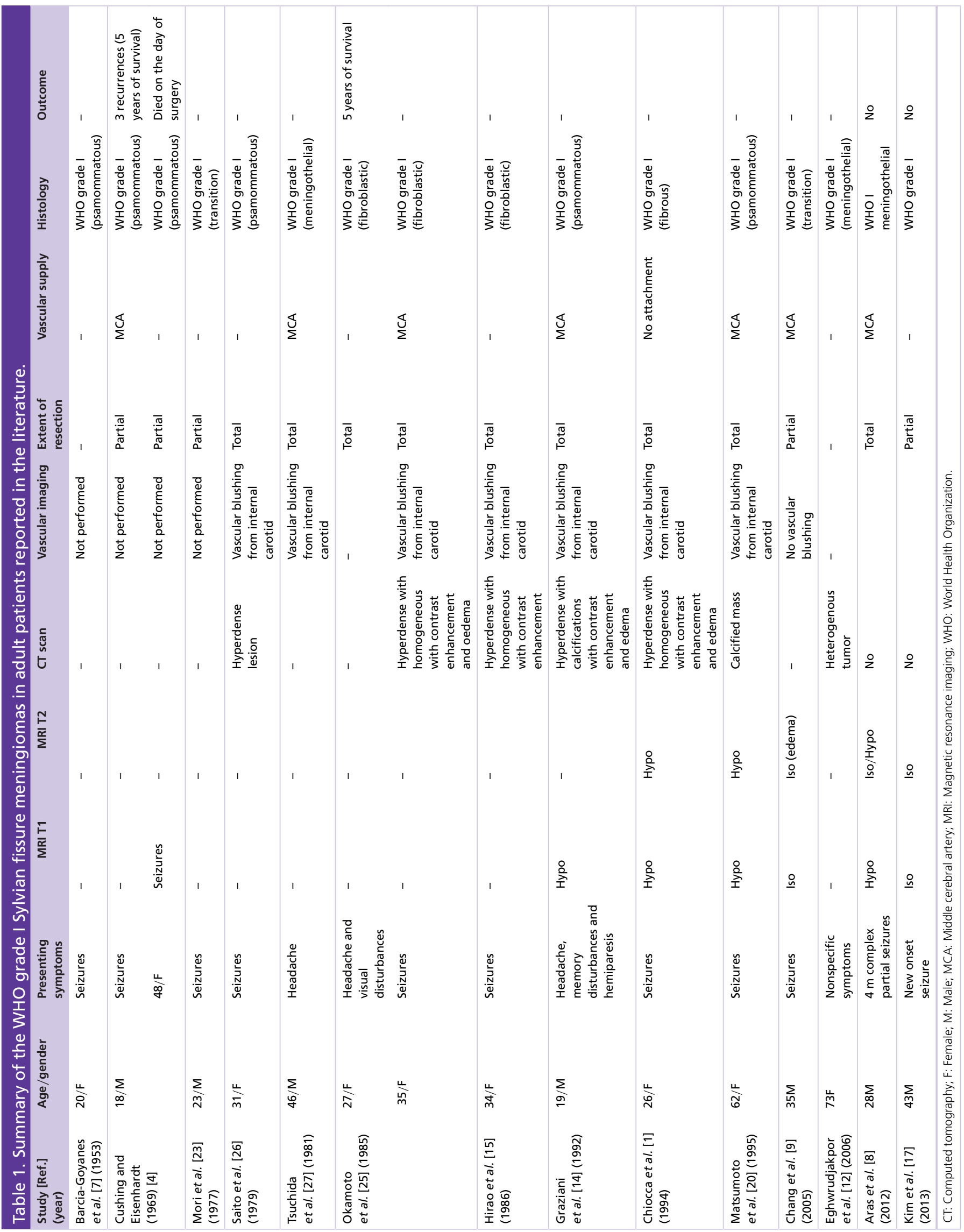




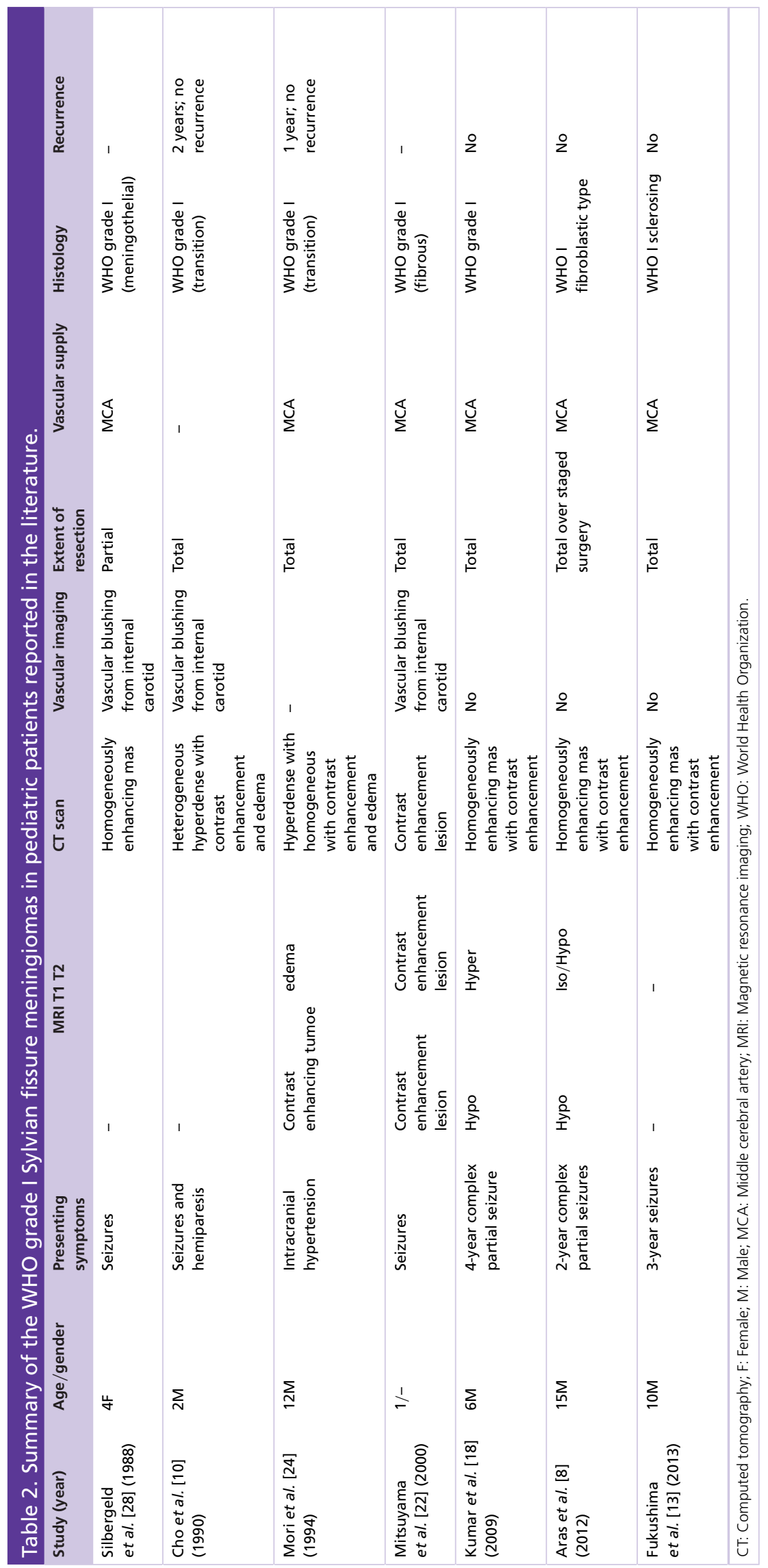




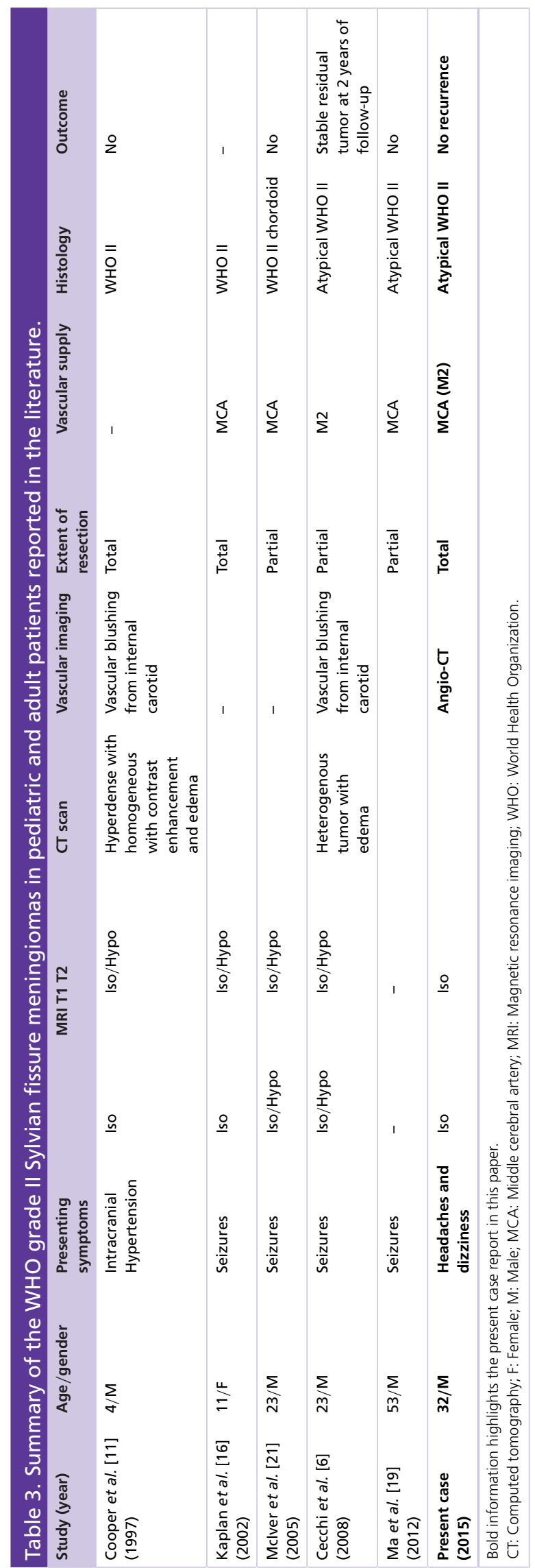




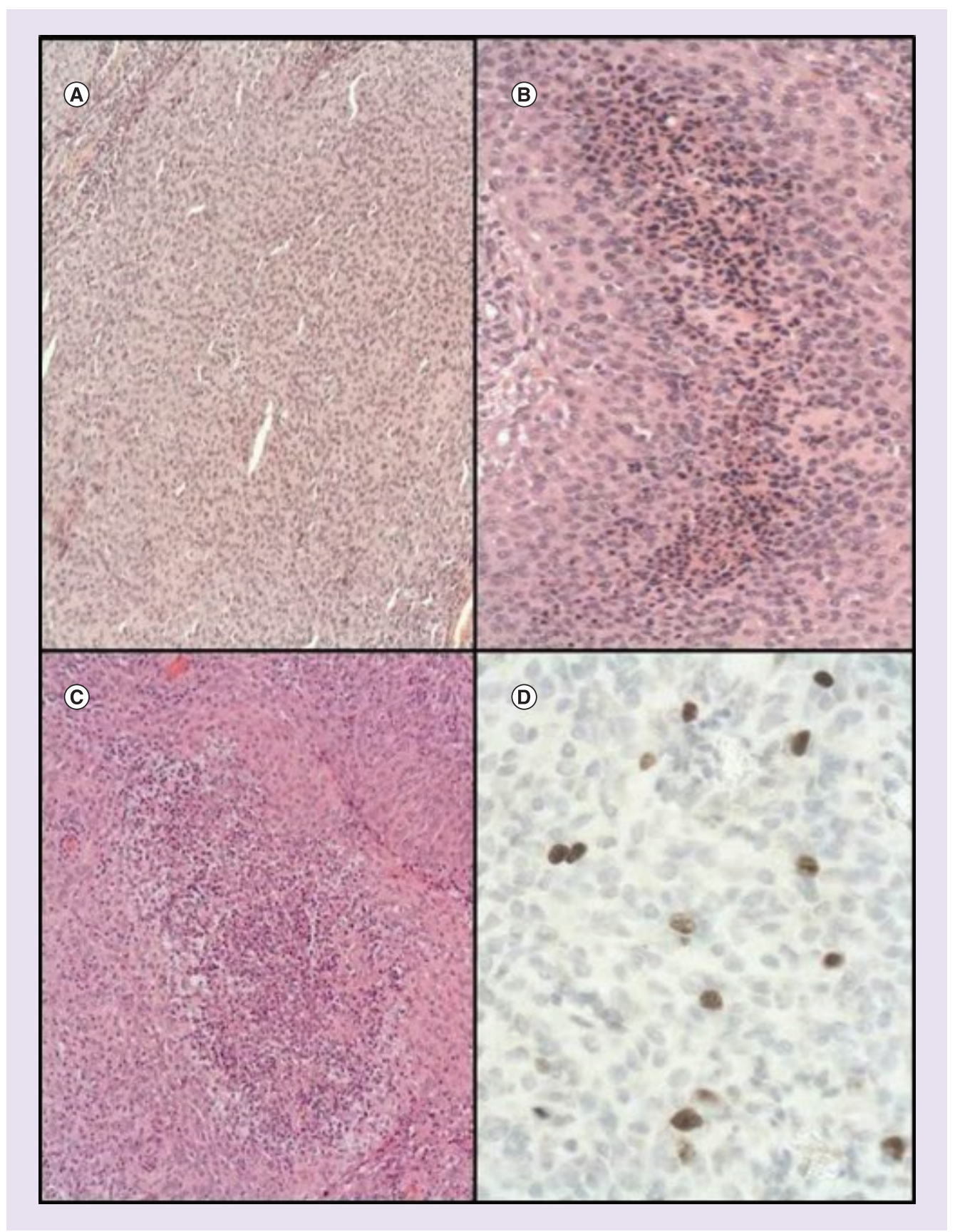

Figure 3. Histology. Haematoxylin and eosin (A-C) revealing an atypical meningioma with a characteristic diffuse arrangement in sheets (A). Areas of small cell changes (B) and tumor necrosis (C). (D) Estimated proliferation index of $6-7 \%$ stained by Ki67.

motor deficits were reported as initial symptoms. In terms of radiological appearance, and if the dural tail is not considered as part of their definition, these lesions display the same features of meningiomas in other regions of the central nervous system. When considering the treatment approach, the absence of dural attachment is attractive in terms of complete surgical resection. Nevertheless, the intimate relation with the MCA vessels has been an important predictor of incomplete resection $(3 / 6)$. A preoperative vessel imaging may help to define the vascular anatomy and the relation between the tumor and the vascular system allowing a better surgical planning. Even though a higher degree of complete resections were obtained in patients with preoperative vascular imaging $(2 / 3 \mathrm{vs}$ $1 / 3)$, the numbers do not allow the drawing of definitive conclusions. The intraoperative use of indocyanine green 


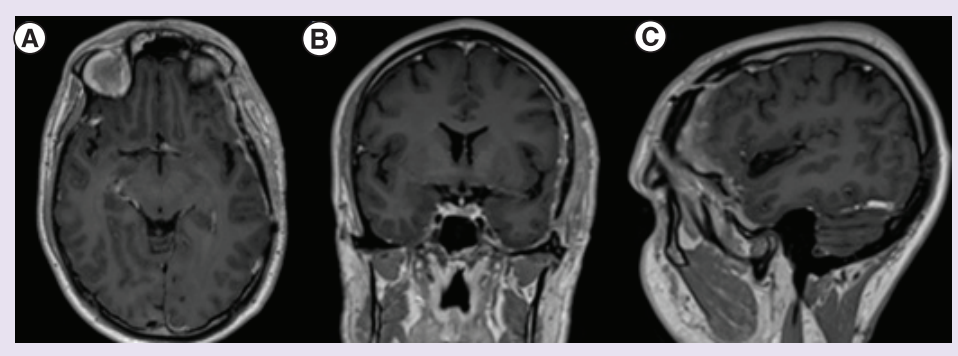

Figure 4. Post-operative imaging. 3 months postoperative axial (A), coronal (B) and sagittal (C) T1-weighted MRI with gadolinium showing total resection of the meningioma and no signs of recurrence. MRI: Magnetic resonance imaging; T1: Superior temporal gyrus.

\begin{tabular}{|c|c|c|c|}
\hline Characteristic & Subcharacteristic & WHO Grade I & WHO Grade II \\
\hline Mean age (years) & & $26.87 \pm 3.90$ & $24.33 \pm 7.01$ \\
\hline \multirow{3}{*}{ Gender (pediatric and adult population) } & Male & 12 & 5 \\
\hline & Female & 10 & 1 \\
\hline & Ratio (M/F) & 1.2 & 5 \\
\hline \multirow[t]{3}{*}{ Symptoms } & Seizures & 17 & 4 \\
\hline & Headaches & 5 & 1 \\
\hline & Intracranial hypertension & 1 & 1 \\
\hline \multirow[t]{2}{*}{ Extent of ressection } & Partial & 6 & 3 \\
\hline & Total & 15 & 3 \\
\hline Total & - & 23 & 6 \\
\hline
\end{tabular}

F: Female; M: Male; SFM: Sylvian fissure meningioma; WHO: World Health Organization.

might be important as a tool for an appropriate identification of the main vessels and the tumor feeders allowing a safer dissection. In those cases, where complete surgical resection was not possible due to intraoperative findings or it was not planned due to preoperative imaging information, we consider that postoperative radiotherapy should be considered, as suggested by recent ongoing trials [29].

\section{Conclusion}

WHO grade II SFMs are a rare subgroup of supratentorial meningiomas. Young males represent the predominant group. Seizures are the most frequent symptom. Imaging shows no dural tail in a background of other common features for meningioma. Surgical treatment is the mainstay of therapy. However, these lesions usually display adherence to the MCA which makes it more difficult to achieve a complete resection. When incomplete resection is performed, postoperative radiotherapy may be considered.

\section{Future perspective}

Grade II SFM surgery is technically demanding and may be related with significant morbidity, if its resection is associated with a vascular injury or important brain invasion. Therefore, the authors believe that an increased number of preoperative imaging studies will be performed in those lesions within the Sylvian fissure to increase the safety of the resection. On the other hand, in those cases where a subtotal resection is performed, postoperative radiotherapy should be considered.

\section{Patient consent}

The patient has given written consent for publication of this case report.

Financial \& competing interests disclosure

The authors have no relevant affiliations or financial involvement with any organization or entity with a financial interest in or financial conflict with the subject matter or materials discussed in the manuscript. This includes employment, consultancies, honoraria, stock ownership or options, expert testimony, grants or patents received or pending, or royalties.

No writing assistance was utilized in the production of this manuscript. 


\section{Informed consent disclosure}

The authors state that they have obtained verbal and written informed consent from the patient/patients for the inclusion of their medical and treatment history within this case report.

\section{Open access}

This work is licensed under the Attribution-NonCommercial-NoDerivatives 4.0 Unported License. To view a copy of this license, visit http://creativecommons.org/licenses/by-nc-nd/4.0/

\section{References}

Papers of special note have been highlighted as: $\bullet$ of interest

1. Chiocca EA, Boviatsis EJ, Westmark RM et al. Deep Sylvian fissure meningioma without dural attachment in an adult: case report. Neurosurgery 35, 944-946 (1994).

2. Saloner D, Uzelac A, Hetts S et al. Modern meningioma imaging techniques. J. Neuro-oncol. 99(3), 333-340 (2010)

3. Claus EB, Bondy ML, Schildkraut JM et al. Epidemiology of intracranial meningioma. Neurosurgery 57(6), 1088-1095 (2005).

- Even though the classification system of these tumors has significantly changed after the publication of this paper, it is a good review of the main distribution and characteristics of the intracranial meningiomas.

4. Cushing H, Eisenhardt L. Meningiomas: Their Classification, Regional Behaviour, Life History and Surgical End Results. Hafner Publishing Company, NYUSA (1960).

- This is book is part of the history of neurosurgery and, therefore, an obligatory read for those who want to clear understand the evolution of our knowledge about these tumors.

5. Zhang J, Chi L, Meng B et al. Meningioma without dural attachment: case report, classification and review of the literature. Surg. Neurol. 67, 535-539 (2007).

6. Cecchi CP, Campello M, Rizzo P et al. (2009) Atypical meninigioma of the Sylvian fissure. J. Clin. Neurosci. 16, 1234-1239 (2009).

7. Barcia-Goyanes JJ, Calvo-Garra W. Meningiomas without dural attachment. Acta Neurochir. 3, 241-247 (1953).

8. Aras Y, Akcakaya MO, Aydoseli A et al. Stages surgery for Sylvian fissure meningiomas without dural attachment: eport of two cases. Clin. Neurol. Neurosurg. 115, 1527-1529 (2013).

9. Chang JE, Kim J, Chang JW et al. Sylvian meningioma without dural attachment in an adult. J. Neuro-oncol. 74, 43-45 (2005).

10. Cho BK, Wang KC, Chang KH et al. Deep Sylvian meningioma in a child. Child's Nerv. Syst. 6, 228-230 (1990).

11. Cooper JR, Marshman LAG, Smith CML et al. Case report: Sylvian fissure meningioma without dural attachment in a 4-year-old child. Clin. Radiol. 52, 874-876 (1997).

12. Eghwrudjakpor PO, Mori K. Sylvian cleft meningioma: surgical approach and postoperative morbidity. Niger. J. Med. 15, 437-440 (2006).

13. Fukushima S, Narita Y, Yonezawa M et al. Short communication: sclerozing meningioma in the deep Sylvian fissure. Brain Tumor Pathol. 31(4), 289-292 (2014).

14. Graziani N, Donnet A, Vincentelli F et al. Deep Sylvian meningioma. Apropos of a case: review of the literature. Neurochirurgie 38, 179-182 (1992).

15. Hirao M, Pka N, Hirashima Y et al. Deep Sylvian meningioma: case report and review of the literature. No Shinkei Geka 14, 1471-1478 (1986).

16. Kaplan SS, Ojemann JG, Park TS. Pediatric Sylvian fissure meningioma. Pediatr. Neurosurg. 36, 275-276 (2002).

17. Kim JY, Lee EJ, Chang HW et al. Deep Sylvian meningioma in a 43-year-old man: a case report. J. Korean Soc. Magn. Reson. Med. 17(4), 308-311 (2013).

18. Kumar GS, Rajshekhar V. Deep Sylvian meningioma: a case report and review of literature. Childs Nerv. Syst. 25, 129-132 (2009).

19. Ma L, Xiao SY, Zhang YK. Atypical meningioma of Sylvian fissure with a 20-year history: a rare case report. Neurol. Sci. 33, 143-145 (2011).

20. Matsumoto S, Yamamoto T, Ban S et al. A case of deep Sylvian meningioma presenting temporal lobe epilepsy. No To Shinkei 47, 503-508 (1995).

21. McIver JI, Scheithauer BW, Atkinson JLD. Deep Sylvian fissure chordoid meningioma: case report. Neurosurgery 57, E1064 (2005).

22. Mitsuyama T, Kasuya H, Kubo O et al. Left Sylvian fissure meningioma in a 1 year-8-month-old child. No Shinkei Geka 28, 459-464 (2000).

23. Mori S, Ishihra H, Sogabe T et al. A case of deep Sylvian meningioma. No Shinkei Geka 5, 385-392 (1977).

24. Mori Y, Shibuya M, Sugita K et al. Deep Sylvian meningioma: a case report of a child. No Shinkei Geka 22, 1147-1151 (1994).

25. Okamoto S, Handa H, Yamashita J et al. Deep Sylvian meningiomas. Surg. Neurol. 23, 303-308 (1985). 
26. Saito A, Mizuno Y, Adachi Y et al. Deep Sylvian psammomeningioma: report of a case. No To Shinkei 31, 79-83 (1979).

27. Tsuchida T, Ito J, Sekiguchi K et al. A case of deep Sylvian meningioma with intracerebral hematoma. No Shinkei Geka 9, 395-400 (1981).

28. Silbergeld D, Berger M, Griffin B. Sylvian fissure meningioma in a child: case report and review of the literature. Pediatr. Neurosurg. 14, 50-53 (1988).

29. Rogers L, Zhang P, Vogelbaum MA et al. Intermediate-risk meningioma: initial outcomes from NRG oncology RTOG 0539. J. Neurosurg. 6, 1-13 (2017).

- The main conclusions of this report support the use of postoperative radiotherapy for newly diagnosed gross-totally resected WHO grade II or recurrent WHO grade I meningioma, irrespective of the resection extent. 